\title{
Placebo-controlled dietary intervention of stress-induced neurovegetative disorders with a specific amino acid composition: a pilot-study
}

\author{
Katrin Chaborski ${ }^{1}$, Norman Bitterlich², Birgit Alteheld ${ }^{1}$, Elke Parsi ${ }^{3}$ and Christine Metzner ${ }^{4,5^{*}}$
}

\begin{abstract}
Background: Psychosocial stress leads to altered neuroendocrine functions, such as serotonergic dysfunction, as well as alterations of the autonomic nervous system and the hypothalamic-pituitary-adrenal (HPA)-axis activity resulting in an imbalance between inhibitory and excitatory neurotransmitters. Poor dietary intake of L-tryptophan as a precursor of serotonin increases sensitivity to stress.
\end{abstract}

Methods: This randomized, double-blind, placebo-controlled study investigated the effect of a specific amino acid composition with micronutrients on neurovegetative disorders and the cardiometabolic risk profile in psychosocially stressed patients. 32 patients (18-65 years) were eligible for protocol analysis. Points in the Psychological Neurological Questionnaire (PNF), clinical and blood parameter, in particular the serotonin level, salivary cortisol levels, and dietary intake were evaluated at baseline and 12 weeks after supplementation.

Results: The intervention in the form of either verum or placebo resulted in both groups in a significant decrease of neurovegetative symptoms. However, patients of the placebo group achieved significantly less points in the PNF compared to the verum group. But the rate of responders ( $\geq 10$ points loss in PNF) was not significantly different between the groups. The macronutrient intake did not differ between verum and placebo group. On average, the HPA-axis was not disturbed in both groups. Blood serotonin indicated in both groups no significant correlation with dietary tryptophan intake or PNF.

Conclusions: Daily supplementation of a specific amino acid composition with micronutrients in psychologically stressed patients resulted in no improvement of neurovegetative disorders as measured by the PNF when compared to the placebo group.

Trial registration: Clinical Trials.gov (NCT01425983)

Keywords: Psychosocial stress, Hypothalamus-Pituitary-Adrenal (HPA)-axis, Sympathetic nervous system (SN), Amino acid composition, Dietary supplement, Psychological Neurological Questionnaire (PNF)

\section{Background}

According to the WHO, psychosocial stress is one of the important health risks of the century; resulting cardiometabolic consequences are enormous [1,2]. Affected persons are usually characterized by neurovegetative disorders as well as metabolic risk factors [1]. Quality of life is reduced by health impairments [2].

\footnotetext{
* Correspondence: christine.metzner@rwth-aachen.de

${ }^{4}$ Department of Internal Medicine III, University Hospital, RWTH,

Pauwelsstraße 44, D-52074 Aachen, Germany

${ }^{5}$ Bonn Education Association for Dietetics r. A., Fuerst-Pueckler-Str. 44 D-50935 Cologne, Germany

Full list of author information is available at the end of the article
}

Physical or psychological stress leads to an increased secretion of corticotropin-releasing hormone (CRH), which affects two important stress systems: the sympathoadrenal medullary system acts by the hormones epinephrine and norepinephrine on cardiovascular functions, thereby increasing resting heart rate and blood pressure; the enabled hypothalamus-pituitary-adrenal (HPA)-axis goes along with a cortisol secretion [3,4]. Somatic effects of increased cortisol level are mainly displayed in inhibiting immune and inflammatory responses, visceral adipose tissue, reduced insulin sensitivity and rising plasma glucose level $[5,6]$. Dysfunction of both systems can affect the circadian 
rhythm of basal cortisol secretion or the cortisol response to a certain stress factor [3], as well as a long-term increase in resting heart rate and blood pressure by hyperactivity of sympathoadrenal medullary system.

The elevated activity of serotonergic neurons in stress diminishes during psychological stress and is associated with mood disorders and depressive symptoms [7]. This is followed by a growing imbalance between the excitatory (norepinephrine, dopamine, glutamate) and inhibitory neurotransmitters (serotonin, gamma-amino-butyric acid [GABA], glycine, taurine). Delivery of amino acids, as precursor of neurotransmitters, within dietary supplements, is an important therapeutic approach and a key feature in nutritional therapy.

The essential amino acid L-tryptophan is the least available amino acid in human nutrition and a precursor of serotonin. In particular, a high protein supply constitutes also the large neutral amino acids (LNAA), which compete with L-tryptophan for the blood brain barrier transporter [8-10]. Central serotonin depletion increases aggressive behaviour and stress-reactivity [11], while poor dietary intake of L-tryptophan also increases sensitivity to stress $[12,13]$. Therefore, an adequate supply with Ltryptophan during psychological stress is necessary [14].
The same applies to taurine as an inhibitory neurotransmitter and ornithine, which stimulates the release of somatotropin, another lacking factor during stress [15].

The effects of micronutrients on mood, mild psychiatric symptoms and stress were discussed in a recently published meta-analysis [16]. The authors concluded that the recommendations for dietary intake should be reviewed while considering these results. In particular B vitamins [17], and few minerals as iron, selenium, magnesium and zinc are mostly analysed. As an important stress-mineral in the central nervous system $[18,19]$, a hypomagnesemia during stress leads to a pathogenic vicious circle [20].

The aim of this study is to investigate, if daily oral administration of an amino acid mixture in combination with micronutrients, specifically designed to decrease neurovegetative disorders, will target these neuroendocrine and metabolic alterations in adults with psychological stress.

\section{Methods}

\section{Study population}

Psychologically stressed women $(n=21)$ and men $(n=13)$ with cardiological disorders were recruited from a

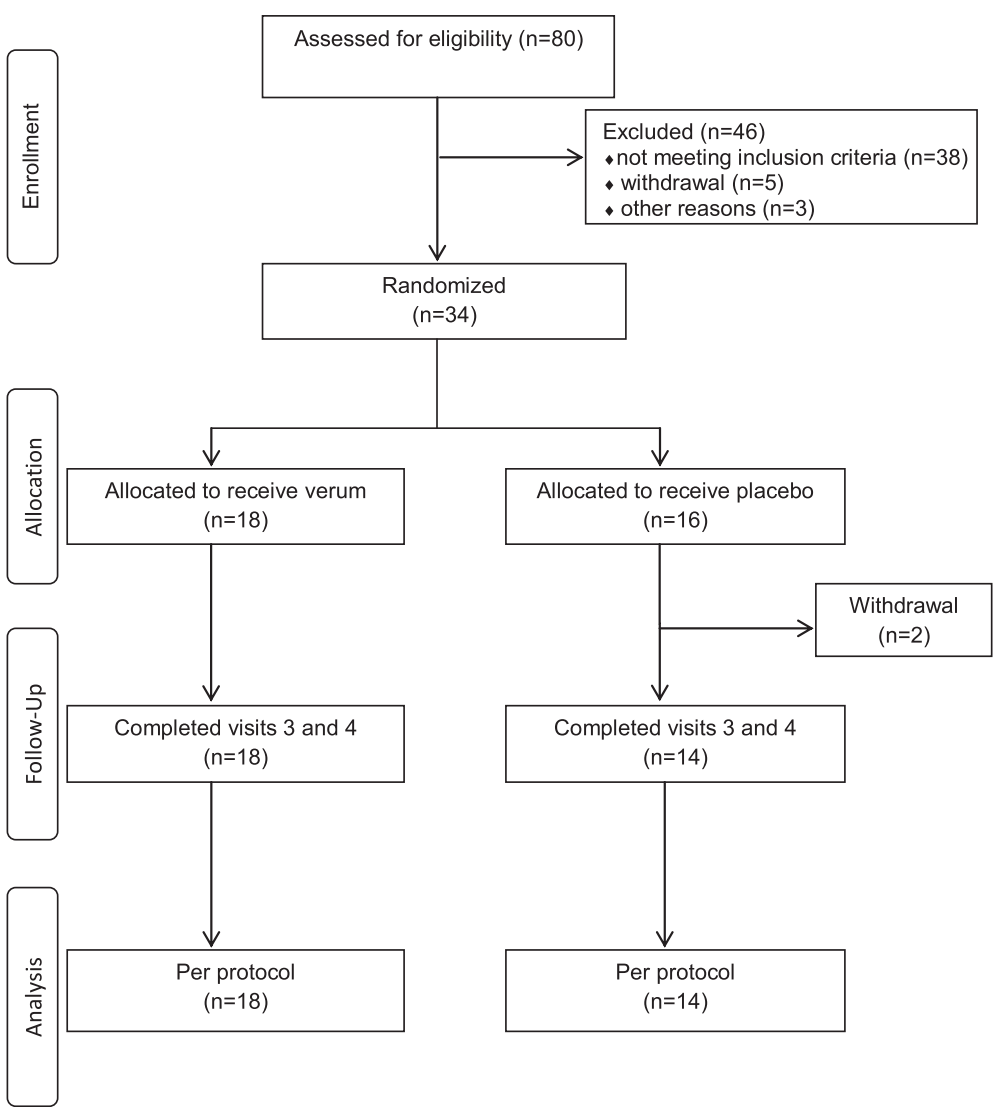

Figure 1 Trial profile. 
cardiological outpatient practice in Berlin, Germany. Psychological stress was defined by neurovegetative disorders determined by a standardized Psychological Neurological Questionnaire (PNF) [21]. Patients aged between 18 and 65 years were included into the study if they obtained $30-50$ points in PNF and a resting heart rate $\geq 70 / \mathrm{min}$, considering the antihypertensive drugs. Exclusion criteria were supplementation with dietary supplements or drugs which contain amino acids, vitamins or other micronutrients, therapy with antipsychotic drugs such as tranquilizer or antidepressants, psychological-neurological or psychiatric therapy and acute and chronic diarrhea. The trial profile of the 80 screened participants is shown in Figure 1.

During 12 weeks of the prospective, controlled, doubleblind trial, participants were required to take one serving of supplement ( $8.9 \mathrm{~g}$ powder; shown in Table 1) per day solved in $200 \mathrm{ml}$ of water. They got a detailed instruction for consumption of the drink, two hours after the last meal (between $8-10 \mathrm{pm}$ ). Compliance was verified by pill counting at week four, eight and twelve.

\section{Psychological neurological questionnaire}

Participants answered the PNF at baseline and after 12 weeks of dietary intervention. A borderline range of psychological stress was classified as $30-50$ points, assessed at inclusion and baseline. Responders were defined by reaching a loss of 10 points or more from baseline to week 12. The questionnaire comprises a total of 38 items which are divided into five categories of neurovegetative disorders (psychoneurovegetative stability, neurological symptoms, impulsion, arousal, concentration). The self-reported symptoms were assessed as total points, as well as for individual categories, ranging from "not at all" (0 points) to "often" (3 points).

\section{Clinical and laboratory methods}

Prior to dietary intervention and after 12 weeks saliva and blood samples, clinical and biochemical data were collected. After a $10 \mathrm{~min}$ resting period, blood pressure and resting heart rate were measured under standardized conditions. The average of three simultaneous measurements was determined. Anthropometric data and venous blood samples were obtained after an overnight fasting period of at least $12 \mathrm{~h}$.

Laboratory Schottdorf MVZ GmbH, Augsburg, Germany, conducted all laboratory analyses (see Additional file 1).

Participants got a detailed instruction for gaining saliva-cortisol samples in the evening (2 hours after last meal, between $8-10 \mathrm{pm}$ ) and morning (30 min after awakening) at baseline and week 12 . Therefore, Salivette ${ }^{\circ}$ sterile cotton swabs were chewed for nearly 1 min until saturation and deposited in collection tubes, subsequently stored in a refrigerator. Measurements were performed by
Table 1 Composition of dietary intervention products

\begin{tabular}{|c|c|c|}
\hline \multicolumn{3}{|c|}{ average values per daily drink ( $8.9 \mathrm{~g}$ powder/0.2 I water) } \\
\hline & Verum & Placebo \\
\hline Energy & $110.8 \mathrm{~kJ} / 26.9 \mathrm{kcal}$ & $146 \mathrm{~kJ} / 34.3 \mathrm{kcal}$ \\
\hline Protein & $3.8 \mathrm{~g}$ & $>0.0 \mathrm{~g}$ \\
\hline Carbohydrates & $0.7 \mathrm{~g}$ & $7.9 \mathrm{~g}$ \\
\hline Fat & $>0.0 \mathrm{~g}$ & $>0.0 \mathrm{~g}$ \\
\hline \multicolumn{3}{|l|}{ Amino acids } \\
\hline L-ornithine & $2000 \mathrm{mg}$ & - \\
\hline Taurine & $1000 \mathrm{mg}$ & - \\
\hline L-tryptophan & $800 \mathrm{mg}$ & - \\
\hline \multicolumn{3}{|l|}{ Vitamins } \\
\hline Vitamin C & $300 \mathrm{mg}$ & - \\
\hline Vitamin B6 & $25 \mathrm{mg}$ & - \\
\hline Vitamin B2 & $25 \mathrm{mg}$ & - \\
\hline Vitamin B1 & $25 \mathrm{mg}$ & - \\
\hline Niacin & $100 \mathrm{mg}$ & - \\
\hline Pantothenic acid & $100 \mathrm{mg}$ & - \\
\hline Folic acid & $800 \mu \mathrm{g}$ & - \\
\hline Vitamin B12 & $50 \mu \mathrm{g}$ & - \\
\hline \multicolumn{3}{|l|}{ Minerals } \\
\hline Magnesium & $300 \mathrm{mg}$ & - \\
\hline Zinc & $15 \mathrm{mg}$ & - \\
\hline Selenium & $100 \mu \mathrm{g}$ & - \\
\hline Chrome & $50 \mu \mathrm{g}$ & - \\
\hline Molybdenum & $50 \mu \mathrm{g}$ & - \\
\hline
\end{tabular}

using microtiter plate reader Sunrise (Tecan, Crailsheim, Germany) and Cortisol ELISA (IBL, Hamburg, Germany).

Three-day food records were reviewed with each participant at baseline and week 12, the average of 3 days was assessed. PRODI 5.5 software (WVG, Stuttgart, Germany) with database BLS II.3 was used for the analysis.

\section{Statistical analysis}

Statistical comparisons were made between groups using nonparametric Mann-Whitney- $U$ test, nonparametric Wilcoxon test was used for data comparison at different time points within groups. Differences in classified variables were tested by $\mathrm{Chi}^{2}$ test. All statistical tests were based on per protocol population and two-sided. Differences were considered significant at $\mathrm{p}<0.05$. Data are reported as mean \pm standard deviation (SD). All analyses were conducted using SPSS ${ }^{\circ}$ for Windows (version 22.0).

The study was approved by the Freiburg Ethics Commission International and was registered with the U.S. National Institutes of Health Clinical Trials.gov (NCT01425983). 
Table 2 Baseline characteristics of psychologically stressed patients in the verum and the placebo group

\begin{tabular}{|c|c|c|c|c|}
\hline & & Verum $(n=18)$ & Placebo $(n=16)$ & V vs. $P$ \\
\hline & & $\bar{x} \pm S D$ & $\bar{x} \pm S D$ & $p$-value \\
\hline \multirow[t]{2}{*}{$\operatorname{sex}(n)$} & $f$ & $10(56 \%)$ & $11(69 \%)$ & $0.429^{a}$ \\
\hline & $\mathrm{m}$ & $8(44 \%)$ & $5(31 \%)$ & \\
\hline Age (years) & & $50 \pm 9$ & $50 \pm 12$ & $0.670^{b}$ \\
\hline Height (cm) & & $172 \pm 8$ & $169 \pm 10$ & $0.313^{b}$ \\
\hline Weight (kg) & & $83 \pm 17$ & $82 \pm 19$ & $0.772^{\mathrm{b}}$ \\
\hline $\mathrm{BMI}\left(\mathrm{kg} / \mathrm{m}^{2}\right)$ & & $28.0 \pm 4.4$ & $28.3 \pm 4.8$ & $0.986^{\mathrm{b}}$ \\
\hline$\leq 24.5 \mathrm{~kg} / \mathrm{m}^{2}$ & & $5(28 \%)$ & $3(19 \%)$ & $0.825^{a}$ \\
\hline $24.6-29.9 \mathrm{~kg} / \mathrm{m}^{2}$ & & $8(44 \%)$ & $8(50 \%)$ & \\
\hline$\geq 30 \mathrm{~kg} / \mathrm{m}^{2}$ & & $5(28 \%)$ & $5(31 \%)$ & \\
\hline WC female $(\mathrm{cm})$ & & $88 \pm 11$ & $83 \pm 11$ & $0.197^{b}$ \\
\hline$W C f \geq 88 \mathrm{~cm}(n)$ & & $7(70 \%)$ & $3(27 \%)$ & $0.050^{\mathrm{a}}$ \\
\hline WC male $(\mathrm{cm})$ & & $100 \pm 11$ & $102 \pm 17$ & $0.524^{b}$ \\
\hline$W C m \geq 102 \mathrm{~cm}(\mathrm{n})$ & & $4(50 \%)$ & $3(60 \%)$ & $0.725^{\mathrm{a}}$ \\
\hline BP systolic (mmHg) & & $135 \pm 10$ & $131 \pm 13$ & $0.175^{b}$ \\
\hline$\geq 130 \mathrm{mmHgci}$ & & $14(78 \%)$ & $6(38 \%)$ & $0.017^{\mathrm{a}}$ \\
\hline BP diastolic $(\mathrm{mmHg})$ & & $85 \pm 10$ & $83 \pm 8$ & $0.463^{b}$ \\
\hline$\geq 85 \mathrm{mmHg}$ & & $9(50 \%)$ & $8(50 \%)$ & $1.000^{\mathrm{a}}$ \\
\hline Pulse pressure & & $51 \pm 9$ & $48 \pm 10$ & $0.313^{b}$ \\
\hline $\mathrm{rHR}(1 / \mathrm{min})$ & & $69 \pm 10$ & $73 \pm 10$ & $0.597^{\mathrm{b}}$ \\
\hline PNF (points) & & $41 \pm 5$ & $39 \pm 6$ & $0.229^{b}$ \\
\hline PN (points) & & $16 \pm 3$ & $16 \pm 4$ & $0.873^{\mathrm{b}}$ \\
\hline Impulsion (points) & & $8 \pm 2$ & $7 \pm 2$ & $0.215^{b}$ \\
\hline Concentration (points) & & $7 \pm 3$ & $7 \pm 3$ & $0.901^{\mathrm{b}}$ \\
\hline Cortisol_m (ng/ml) ${ }^{c}$ & & $7.5 \pm 4.4$ & $6.1 \pm 3.3$ & $0.552^{\mathrm{b}}$ \\
\hline Cortisol_e $(\mathrm{ng} / \mathrm{ml})^{c}$ & & $1.2 \pm 1.5$ & $1.2 \pm 1.2$ & $0.711^{\mathrm{b}}$ \\
\hline$\Delta$ Cortisol $(\mathrm{ng} / \mathrm{ml})^{\mathrm{c}}$ & & $6.3 \pm 5.0$ & $5.0 \pm 3.8$ & $0.652^{b}$ \\
\hline Serotonin $\left(\mu \mathrm{g} / \mathrm{l}^{\mathrm{c}}\right.$ & & $180 \pm 84$ & $180 \pm 47$ & $0.444^{b}$ \\
\hline CRP sensitive (mg/l) & & $2.9 \pm 3.1$ & $6.6 \pm 7.9$ & $0.202^{\mathrm{b}}$ \\
\hline GGT (U/I) & & $45 \pm 48$ & $21 \pm 11$ & $0.046^{b}$ \\
\hline $\mathrm{TC}(\mathrm{mg} / \mathrm{dl})$ & & $219 \pm 36$ & $217 \pm 43$ & $0.772^{b}$ \\
\hline $\mathrm{HDL}-\mathrm{C}(\mathrm{mg} / \mathrm{dl})$ & & $59.0 \pm 26.8$ & $61.4 \pm 18.0$ & $0.356^{\mathrm{b}}$ \\
\hline $\mathrm{LDL}-\mathrm{C}(\mathrm{mg} / \mathrm{dl})$ & & $133 \pm 34$ & $132 \pm 42$ & $0.932^{\mathrm{b}}$ \\
\hline LDL-C/HDL-C & & $2.6 \pm 1.0$ & $2.3 \pm 0.9$ & $0.330^{\mathrm{b}}$ \\
\hline $\mathrm{TG}(\mathrm{mg} / \mathrm{dl})$ & & $162 \pm 88$ & $145 \pm 57$ & $0.851^{\mathrm{b}}$ \\
\hline TG/HDL-C & & $3.4 \pm 2.6$ & $2.8 \pm 1.8$ & $0.621^{\mathrm{b}}$ \\
\hline $\mathrm{FPG}(\mathrm{mg} / \mathrm{dl})$ & & $99 \pm 28$ & $97 \pm 16$ & $0.798^{\mathrm{b}}$ \\
\hline $\mathrm{HbA1} 1_{c}(\%)$ & & $5.8 \pm 0.9$ & $5.7 \pm 0.3$ & $0.330^{b}$ \\
\hline HOMA-Index & & $3.2 \pm 3.3$ & $2.0 \pm 1.2$ & $0.330^{\mathrm{b}}$ \\
\hline Insulin-ECLIA ( $\mu \mathrm{U} / \mathrm{ml})$ & & $11.9 \pm 8.1$ & $8.1 \pm 4.1$ & $0.266^{b}$ \\
\hline
\end{tabular}

abbreviations used: BP, blood pressure; BMI, body mass index; Cortisol:_m, morning; _e, evening; $\triangle$ Cortisol, cortisol difference morning-evening; CRP sensitive, C-reactive protein sensitive; ECLIA, Enhanced Chemiluminescent Immunoassay; FPG, fasting plasma glucose; GGT, gamma-glutamyltransferase; $\mathrm{HbA1}{ }_{c}$, glycated haemoglobin A1 $;$; HDL-C, HDL cholesterol; HOMA-Index, Homeostasis Model Assessment-Index; LDL-C, LDL cholesterol; PNF, Psychological Neurological; Questionnaire; PN, psycho-neurovegetative stability; rHR, resting Heart rate; TC, total cholesterol; TG, triglycerides; WC, waist circumference.p-value: ${ }^{\mathrm{a}} \mathrm{Chi}{ }^{2}$ test; ${ }^{\mathrm{b}}$ Mann-Whitney-U test; $^{\mathrm{C}}{ }^{\mathrm{d}}$ data not available for all patients (numbers listed in Additional file 2 ). 
Table 3 Changing of patient's characteristics: comparison of values before and after dietary intervention

\begin{tabular}{|c|c|c|c|c|c|c|c|}
\hline & Verum $(n=$ & & & Placebo (n & & & V vs. $P$ \\
\hline & $\bar{x} \pm S D$ & & & $\bar{x} \pm S D$ & & & week 12 \\
\hline & Baseline & Week $12^{a}$ & Diff & Baseline & Week $12^{a}$ & Diff & $p^{\mathbf{b}}$ \\
\hline Weight (kg) & $83.4 \pm 16.5$ & $84.5 \pm 17.1^{*}$ & $1.1 \pm 1.7$ & $81.7 \pm 19.9$ & $82.2 \pm 19.5$ & $0.4 \pm 1.2$ & 0.722 \\
\hline $\mathrm{BMI}\left(\mathrm{kg} / \mathrm{m}^{2}\right)$ & $28.0 \pm 4.4$ & $28.4 \pm 4.6^{*}$ & $0.4 \pm 0.5$ & $28.8 \pm 4.9$ & $29.0 \pm 4.7$ & $0.2 \pm 0.4$ & 0.750 \\
\hline$W C(\mathrm{~cm}) f$ & $88 \pm 11$ & $89 \pm 11$ & $1 \pm 2$ & $83 \pm 11$ & $84 \pm 12$ & $1 \pm 2$ & 0.218 \\
\hline Female $\geq 88 \mathrm{~cm}(\% \mathrm{n})^{+}$ & $7(70 \%)$ & $7(70 \%)$ & 0 & $2(20 \%)$ & $4(40 \%)$ & 2 & 0.123 \\
\hline$W C(\mathrm{~cm}) \mathrm{m}$ & $100 \pm 11$ & $101 \pm 11$ & $1 \pm 2$ & $109 \pm 11$ & $108 \pm 12$ & $-1 \pm 1$ & 0.368 \\
\hline Male $\geq 102 \mathrm{~cm}(\% \mathrm{n})^{+}$ & $4(50 \%)$ & $4(50 \%)$ & 0 & $3(75 \%)$ & $4(100 \%)$ & 1 & 0.279 \\
\hline BP systolic (mmHg) & $135 \pm 10$ & $133 \pm 13$ & $-2 \pm 11$ & $130 \pm 14$ & $132 \pm 17$ & $2 \pm 12$ & 0.955 \\
\hline$\geq 130$ mmHg (\%n) & $14(78 \%)$ & $10(56 \%)$ & -4 & $5(36 \%)$ & $10(71 \%)$ & 5 & 0.681 \\
\hline BP diastolic (mmHg) & $85 \pm 10$ & $85 \pm 9$ & $0 \pm 8$ & $83 \pm 8$ & $84 \pm 10$ & $0 \pm 10$ & 0.512 \\
\hline Pulse pressure & $51 \pm 9$ & $50 \pm 7$ & $-1 \pm 11$ & $46 \pm 10$ & $49 \pm 11$ & $3 \pm 8$ & 0.357 \\
\hline $\mathrm{rHr}(1 / \mathrm{min})$ & $69 \pm 10$ & $72 \pm 9$ & $3 \pm 6$ & $73 \pm 10$ & $72 \pm 12$ & $-1 \pm 9$ & 0.808 \\
\hline PNF & $41 \pm 5$ & $33 \pm 8^{*}$ & $-8 \pm 9$ & $39 \pm 6$ & $22 \pm 9^{*}$ & $-17 \pm 12$ & 0.003 \\
\hline PN & $16 \pm 3$ & $12 \pm 4^{*}$ & $-3 \pm 3$ & $16 \pm 3$ & $10 \pm 5^{*}$ & $-7 \pm 5$ & 0.168 \\
\hline Cortisol_m $(\mathrm{ng} / \mathrm{ml})^{c}$ & $7.5 \pm 4.4$ & $6.6 \pm 4.1$ & $-0.5 \pm 3.6$ & $6.0 \pm 3.4$ & $5.3 \pm 3.4$ & $-0.7 \pm 3.4$ & 0.425 \\
\hline Cortisol_e $(\mathrm{ng} / \mathrm{ml})^{\mathrm{c}}$ & $1.2 \pm 1.5$ & $1.5 \pm 1.6$ & $0.6 \pm 1.7$ & $1.2 \pm 1.2$ & $0.9 \pm 0.9$ & $-0.3 \pm 0.8$ & 0.533 \\
\hline$\Delta$ Cortisol $(\mathrm{ng} / \mathrm{ml})^{c}$ & $6.3 \pm 5.0$ & $5.6 \pm 4.8$ & $-0.6 \pm 4.1$ & $4.8 \pm 3.9$ & $4.4 \pm 3.5$ & $-0.4 \pm 3.5$ & 0.454 \\
\hline Serotonin $\left(\mu \mathrm{g} / \mathrm{l}^{c}\right.$ & $171 \pm 90$ & $185 \pm 100$ & $5 \pm 34$ & $180 \pm 50$ & $190 \pm 64$ & $11 \pm 30$ & 0.356 \\
\hline CRP sensitive (mg/l) & $2.9 \pm 3.1$ & $2.4 \pm 2.6$ & $-0.7 \pm 2.9$ & $7.1 \pm 8.0$ & $6.0 \pm 7.8$ & $-1.0 \pm 2.5$ & 0.120 \\
\hline GGT (U/l) & $45 \pm 48$ & $58 \pm 71^{*}$ & $13 \pm 25$ & $23 \pm 11$ & $24 \pm 14$ & $1.6 \pm 4.8$ & 0.180 \\
\hline $\mathrm{TC}(\mathrm{mg} / \mathrm{dl})$ & $219 \pm 36$ & $211 \pm 40$ & $-8 \pm 22$ & $217 \pm 43$ & $216 \pm 36$ & $-1 \pm 20$ & 0.561 \\
\hline $\mathrm{HDL}-\mathrm{C}(\mathrm{mg} / \mathrm{dl})$ & $59 \pm 27$ & $59 \pm 26$ & $0 \pm 6$ & $62 \pm 19$ & $61 \pm 14$ & $-0.8 \pm 9.3$ & 0.301 \\
\hline LDL-C (mg/dl) & $133 \pm 34$ & $125 \pm 36$ & $-8 \pm 19$ & $132 \pm 44$ & $132 \pm 32$ & $0 \pm 21$ & 0.561 \\
\hline LDL-C/HDL-C & $2.6 \pm 1.0$ & $10.1 \pm 32.9$ & $-0.4 \pm 0.8$ & $2.3 \pm 0.9$ & $2.3 \pm 1.0$ & $0 \pm 0.5$ & 0.561 \\
\hline $\mathrm{TG}(\mathrm{mg} / \mathrm{dl})$ & $162 \pm 88$ & $153 \pm 87$ & $-9 \pm 39$ & $145 \pm 61$ & $136 \pm 39$ & $-10 \pm 42$ & 0.808 \\
\hline $\mathrm{TG} / \mathrm{HDL}-\mathrm{C}$ & $3.4 \pm 2.6$ & $6.0 \pm 11.9$ & $2.6 \pm 11.6$ & $2.9 \pm 2.0$ & $2.5 \pm 1.2$ & $-0.4 \pm 1.1$ & 0.536 \\
\hline FPG (mg/dl) & $99 \pm 28$ & $102 \pm 44$ & $3 \pm 17$ & $97 \pm 17$ & $92 \pm 10$ & $-5 \pm 18$ & 0.891 \\
\hline $\mathrm{HbA1}_{c}(\%)$ & $5.8 \pm 0.9$ & $5.8 \pm 0.9$ & $0.1 \pm 0,2$ & $5.7 \pm 0.3$ & $5.7 \pm 0.3$ & $0 \pm 0.3$ & 0.750 \\
\hline HOMA-Index & $3.2 \pm 3.3$ & $3.6 \pm 3.7$ & $0.4 \pm 2.6$ & $2.2 \pm 1.2$ & $2.5 \pm 1.9$ & $0.3 \pm 1.8$ & 0.488 \\
\hline Insulin-ECLIA ( $\mu \mathrm{U} / \mathrm{ml})$ & $11.9 \pm 8.1$ & $2.3 \pm 1.0$ & $-1.3 \pm 6.1$ & $8.8 \pm 4.0$ & $10.5 \pm 7.5$ & $1.8 \pm 6.5$ & 0.955 \\
\hline
\end{tabular}

abbreviations used: BP, blood pressure; BMI, body mass index; Cortisol:_m, morning; _e, evening; $\Delta$ Cortisol, cortisol difference morning-evening; CRP sensitive, C-reactive protein sensitive; Diff, difference; ECLIA, Enhanced Chemiluminescent Immunoassay; FPG, fasting plasma glucose; GGT, gamma-glutamyltransferase; $\mathrm{HbA}_{\mathrm{c}}$, glycated haemoglobin A1 $1_{c} \mathrm{HDL}-\mathrm{C}, \mathrm{HDL}$ cholesterol; HOMA-Index, Homeostasis Model Assessment-Index; LDL-C, LDL cholesterol; PNF, Psychological Neurological Questionnaire; PN, psycho-neurovegetative stability; rHR, resting heart rate; TC, total cholesterol; TG, triglycerides; WC, waist circumference. p-value: ${ }^{a}$ Wilcoxon-test within groups, ${ }^{b}$ Mann-Whitney- $U$ test: ${ }^{*} p<0.05$.

'data not available for all patients (numbers listed in Additional file 2).

${ }^{+}$Verum: women $n=10$, men $n=8$; Placebo: women $n=10$, men $n=4$.

\section{Results}

\section{Patient's characteristics}

A total of 34 patients were randomized into verum and placebo groups, 32 patients were left for protocol analysis (Figure 1). Two patients of the placebo group discontinued the study as early dropouts, both for personal reasons. Daily servings were well tolerated by the majority of patients, one patient of the verum group got a cholecystitis during intervention, two patients of each group indicated gastrointestinal complaints or nausea in the morning. There was no correlation to supplementation assumed.

The patient's characteristics at baseline are shown in Table 2. The difference of GGT was mainly caused by extreme values in the verum group. About three quarters of patients were overweight. Systolic blood pressure indicated an increased activity of sympathoadrenal system in both groups. But only at inclusion, most patients of verum group met the criteria of elevated resting heart 
Table 4 Dietary intake before and after intervention

\begin{tabular}{|c|c|c|c|c|c|}
\hline & \multicolumn{2}{|c|}{ Verum $(n=18) \bar{x} \pm S D$} & \multicolumn{2}{|c|}{ Placebo $(n=14) \bar{x} \pm S D$} & \multirow{2}{*}{$\begin{array}{l}\text { V vs. P week } 12 \\
p^{\mathrm{b}}\end{array}$} \\
\hline & Baseline & Week $12^{\mathrm{a}}$ & Baseline & Week $12^{\mathrm{a}}$ & \\
\hline Energy (kcal) & $2627 \pm 694$ & $2427 \pm 556$ & $2453 \pm 625$ & $2601 \pm 937$ & 0.779 \\
\hline Carbohydrates (g) & $280 \pm 88$ & $260 \pm 77$ & $248 \pm 72$ & $275 \pm 114$ & 0.543 \\
\hline Protein (g) & $103 \pm 23$ & $97 \pm 28$ & $101 \pm 25$ & $106 \pm 33$ & 0.470 \\
\hline Fat (g) & $114 \pm 40$ & $97 \pm 25$ & $107 \pm 42$ & $107 \pm 41$ & 0.879 \\
\hline SFA (g) & $43.1 \pm 12.3$ & $37.5 \pm 14.0$ & $41.4 \pm 15.9$ & $38.0 \pm 9.4$ & 0.543 \\
\hline MUFA (g) & $41.2 \pm 19.5$ & $39.7 \pm 19.3$ & $35.7 \pm 18.1$ & $35.2 \pm 10.8$ & 0.909 \\
\hline PUFA (g) & $18.8 \pm 9.6$ & $18.3 \pm 8.9$ & $15.5 \pm 7.5$ & $15.8 \pm 5.9$ & 0.543 \\
\hline n-6 FA (g) & $16.4 \pm 9.1$ & $15.9 \pm 8.3$ & $12.7 \pm 6.6$ & $13.8 \pm 5.7$ & 0.569 \\
\hline $\mathrm{n}-3$ FA (g) & $2.0 \pm 1.1$ & $2.1 \pm 0.9$ & $2.5 \pm 2.2$ & $1.7 \pm 0.8$ & 0.166 \\
\hline
\end{tabular}

abbreviations used: MUFA, monounsaturated fatty acids; n-3 FA, omega-3 fatty acids; n-6 FA, omega-6 fatty acids; PUFA, polyunsaturated fatty acids; SFA, saturated fatty acids.

p-value: ${ }^{\mathrm{a}}$ Wilcoxon-test within groups, ${ }^{\mathrm{b}}$ Mann-Whitney- $U$ test.

rate $(74 \pm 10 / \mathrm{min})$, which allowed, just with some limitations, to state an activated sympathoadrenal system. A significant influence on patients with antihypertensive drugs had been excluded.

Additionally, the HPA-axis was not disturbed as shown by saliva cortisol measurement and a serotonin deficiency was not detectable in the blood (Table 2 and Additional file 2). Blood serotonin indicated in both groups no significant correlation with dietary tryptophan intake or PNF. Thus, this initial situation was not as expected and complicated the data interpretation.

\section{Psychological neurological questionnaire}

After 12 weeks of supplementation, patients of both groups indicated a significant improvement of neurovegetative disorders. Patients of the placebo group achieved significantly less points in the PNF compared to the verum group (Table 3 and Additional file 2). However, the rate of responders ( $\geq 10$ points loss in PNF) was not significantly different between verum $(\mathrm{n}=7)$ and placebo group $(\mathrm{n}=9$; $p=0.154)$.

\section{Nutritional impact}

Absolute values of energy- and macronutrient-intake did not significantly differ between verum and placebo group (Table 4). Overall, the unfavourable fat-intake based on a poor ratio of $n-6$ fatty acids $/ n-3$ fatty acids (n-6 FA/n-3 FA) and a large share of saturated fatty acids (SFA). Even after taking the supplements, there was no evidence of a significant change in protein-, fator SFA-intake (Table 4).

\section{Discussion}

The present study investigated whether daily supplementation of an amino acid mixture with micronutrients specifically decreases neurovegetative disorders in psychologically stressed adults as compared to a placebo. After 12-week dietary intervention both groups demonstrated a significant reduction of characteristic symptoms. Surprisingly the patients of the placebo group reported significantly less points than the patients of verum group.

The PNF could be discussed as a tool for establishing chronic stress [22]. Here, we used a borderline range of psychological stress for determining chronically stressed patients. In order to detect the verum's effectiveness, pre-post intervention changes in total number of points were analysed, as well as the rate of responder. Considering the results presented here, it seems to be somewhat difficult to distinguish between a placebo effect and the actual efficacy. Two-thirds of the placebo group presented a significantly greater decrease in total points than in the verum group. This placebo effect cannot be explained out of the baseline-situation in comparison to the verum group.

The assumptions of a disturbed HPA-axis and a serotonin deficiency were not met for most patients. Therefore, the diagnosis of psychological stress was merely confirmed by the PNF and in a diminished manner by elevated resting heart rate. Although another clinical study showed that there seemed to be no correlations of blood serotonin and central serotonin in humans [23]. Considering these results, in following studies the blood concentration of amino acids and micronutrients would be even better parameter to control an improvement, especially the relation of available tryptophan to the remaining LNAA [24].

Many unpredictable effects such as changes in nutritional behaviour over time, which are difficult to control for, bias results even in carefully designed studies [25]. The nutritional effect of carbohydrates and protein on mood has been discussed for some time [26-28]. A highfat diet is supposed to have a protective effect on 
chronic stress exposure in mice [29]. Therefore, it could be assumed that the composition of consumed food affected mood, behaviour and neurovegetative disorders in the psychologically stressed patients of our study.

Although there were no significant differences in nutritional intake between the groups, the SFA-intake was remarkable. Other authors stated that the impact of a self-medication by eating palatable foods during chronic stress, leads to a high-fat diet in these patients, thereby protecting against stress-induced effects [30,31]. It has also been shown in rodents that a high-fat diet protects against the effects of chronic stress exposure $[32,33]$ while the animals on a low-fat diet reacted with weight gain and increased caloric intake [32]. Psychologically stressed patients often respond with weight gain and an unconscious change of their eating behaviour $[34,35]$. These changes couldn't be observed in this study population.

Although considering the protective effects of a high-fat diet in short-term, the increased fat-intake will become habitual $[36,37]$ and thus will lead to a deterioration of the cardiometabolic situation in long-term $[38,39]$. The aftereffects of a long-lasting high-fat diet were shown in rodents and include increasing levels of insulin, insulin resistance and mild hyperglycemia [24,32,40,41].

As a study limitation, there would be to mention the small sample size, which decreases the statistical power, in particular for the comparison of subgroups but also for the detection of marginal changes. The low participation could be attributed to the impacts of chronic stress and should be recognized as a non-participation bias. Concurrently, the selection of participants was locally limited, and most of them were handicapped by cardiological therapy, although significant impairment by antihypertensive drugs was excluded.

The connection between a high-fat diet and chronic stress exposure is widely examined in studies with rodents $[29,33]$. In this pilot study, we showed that these correlations could also exist in psychologically stressed humans and therefore, provided some clues for further investigations in a larger cohort.

\section{Conclusions}

Daily supplementation of a specific amino acid composition with micronutrients in psychologically stressed patients resulted in no improvement of neurovegetative disorders as measured by the PNF when compared to the placebo group.

\section{Additional files}

Additional file 1: Laboratory analyses.

Additional file 2: Valid numbers for cortisol and serotonin values.

Considering Tables 2 and 3: 'data not available for all patients. Missing cortisol values due to material deficiency for measuring. Missing serotonin values due to value below limit of detection $(<16 \mu \mathrm{g} / \mathrm{l})$.

\section{Abbreviations}

BMI: Body mass index; $\mathrm{CRH}$ : Corticotropin-releasing hormone; CRP: C-reactive protein; FA: Fatty acids; GGT: Gamma-glutamyltransferase; HOMA-Index: Homeostasis model assessment index; HPA: Hypothalamic-pituitary-adrenal-axis; LNAA: Large neutral amino acids; n-3 FA: Omega-3 fatty acids; PNF: Psychological Neurological Questionnaire; PUFA: Polyunsaturated fatty acids; SFA: Saturated fatty acids; SD: Standard deviation; SN: Sympathetic nervous system.

\section{Competing interests}

The authors declare that they have no competing interests.

\section{Authors' contributions}

CM designed research. EP conducted the study. KC prepared the paper and conducted the statistical analysis, supported and supervised by NB. CM, NB and BA contributed to the interpretation of the data and revised the manuscript. All authors contributed to the final version of the paper and gave their approval for publication of the final version.

\section{Acknowledgements}

We would like to acknowledge Daniela Roesler, Bonn Education Association for Dietetics r. A., for their analysis on the dietary intake and their monitoring on the study.

This work was funded by a research contract from Kyberg Vital GmbH, Unterhaching, Germany.

\section{Funding}

Kyberg Vital GmbH, Unterhaching, Germany.

\section{Author details}

${ }^{1}$ Department of Nutrition and Food Sciences, Nutritional Physiology, University of Bonn, Endenicher Allee 11-13, D-53115 Bonn, Germany. 2Department of Biostatistics, Medicine and Service Ltd, Boettcherstr. 10, D-09117 Chemnitz, Germany. ${ }^{3}$ Outpatient Practice of Cardiology/Angiology, Suermondtstr. 13, D-13053 Berlin, Germany. ${ }^{4}$ Department of Internal Medicine III, University Hospital, RWTH, Pauwelsstraße 44, D-52074 Aachen, Germany. ${ }^{5}$ Bonn Education Association for Dietetics r. A., Fuerst-Pueckler-Str. 44, D-50935 Cologne, Germany.

Received: 1 August 2014 Accepted: 24 April 2015

Published online: 06 May 2015

\section{References}

1. Roohafza H, Sadeghi M, Naghnaeian M, Shokouh P, Ahmadi A, Sarrafzadegan N. Relationship between metabolic syndrome and its components with psychological distress. Int J Endocrinol. 2014;2014:203463.

2. Hamer M, Molloy GJ, Stamatakis E. Psychological distress as a risk factor for cardiovascular events: pathophysiological and behavioral mechanisms. J Am Coll Cardiol. 2008;52:2156-62.

3. Lederbogen F, Deuschle Fuer Die Kora-Studiengruppe M. Dysfunction of the hypothalamus-pituitary-adrenal system-background variable of relevant cardiovascular risk factors?-description of a cooperative project. Gesundheitswesen. 2005;67 Suppl 1:S94-7.

4. Almeida DM, McGonagle K, King H. Assessing daily stress processes in social surveys by combining stressor exposure and salivary cortisol. Biodemography Soc Biol. 2009:55:219-37.

5. Girod JP, Brotman DJ. Does altered glucocorticoid homeostasis increase cardiovascular risk? Cardiovasc Res. 2004;64:217-26.

6. Björntorp P, Rosmond R. Obesity and cortisol. Nutrition. 2000;16:924-36.

7. Takeda E, Terao J, Nakaya Y, Miyamoto K, Baba Y, Chuman H, et al. Stress control and human nutrition. J Med Invest. 2004;51:139-45.

8. Fernstrom JD, Wurtman RJ. Brain serotonin content: physiological regulation by plasma neutral amino acids. Science. 1972;178:414-6.

9. Fernstrom JD. Branched-chain amino acids and brain function. J Nutr. 2005; 135:1539S-46S.

10. Wurtman R, Hefti F, Melamed E. Precursor control of neurotransmitter synthesis. Pharmacol Rev. 1980;32:315-35. 
11. Siever LJ. Neurobiology of aggression and violence. Am J Psychiatry. 2008;165:429-42.

12. Tanke MA, Alserda E, Doornbos B, van der Most PJ, Goeman K, Postema F, et al. Low tryptophan diet increases stress-sensitivity, but does not affect habituation in rats. Neurochem Int. 2008;52:272-81.

13. Jans LA, Riedel WJ, Markus CR, Blokland A. Serotonergic vulnerability and depression: assumptions, experimental evidence and implications. Mol Psychiatry. 2007;12:522-43.

14. Markus CR. Dietary amino acids and brain serotonin function; implications for stress-related affective changes. Neuromolecular Med. 2008;10:247-58.

15. Miyabo S, Hisada T, Asato T, Mizushima N, Ueno K. Growth hormone and cortisol responses to psychological stress: comparison of normal and neurotic subjects. J Clin Endocrinol Metab. 1976;42:1158-62.

16. Long SJ, Benton D. Effects of vitamin and mineral supplementation on stress, mild psychiatric symptoms, and mood in nonclinical samples: a meta-analysis. Psychosom Med. 2013;75:144-53.

17. Camfield DA, Wetherell MA, Scholey AB, Cox KH, Fogg E, White DJ, et al. The effects of multivitamin supplementation on diurnal cortisol secretion and perceived stress. Nutrients. 2013:5:4429-50.

18. Sartori SB, Whittle N, Hetzenauer A, Singewald N. Magnesium deficiency induces anxiety and HPA axis dysregulation: modulation by therapeutic drug treatment. Neuropharmacology. 2012;62:304-12.

19. Serefko A, Szopa A, Wlaź P, Nowak G, Radziwoń-Zaleska M, Skalski M, et al. Magnesium in depression. Pharmacol Rep. 2013;65:547-54.

20. Seelig MS. Consequences of magnesium deficiency on the enhancement of stress reactions; preventive and therapeutic implications (a review). J Am Coll Nutr. 1994;13:429-46.

21. Schneider $H$, Wall $H$, Zeller HJ. The psychologiconeurological questionnaire-A screeining method for examinations of ability and control. ZKM. 1988;43:1321-2.

22. Wall $H$, Schneider $H$. Relationship of screening and differential diagnosis-a critical study of methods exemplified by the psychologic-neurologic questionnaire and a diagnostic psychologic follow-up program. Z Gesamte Hyg. 1991;37:17-9.

23. Cleare AJ, Bond AJ. The effect of tryptophan depletion and enhancement on subjective and behavioural aggression in normal male subjects. Psychopharmacology (Berl). 1995;118:72-81.

24. Chalkley SM, Hettiarachchi M, Chisholm DJ, Kraegen EW. Long-term high-fat feeding leads to severe insulin resistance but not diabetes in Wistar rats. Am J Physiol Endocrinol Metab. 2002;282:E1231-8.

25. Zunft HJ, Lueder W, Harde A, Haber B, Graubaum HJ, Koebnick C, et al. Carob pulp preparation rich in insoluble fibre lowers total and LDL cholesterol in hypercholesterolemic patients. Eur J Nutr. 2003;42:235-42.

26. Lemmens SG, Born JM, Martens EA, Martens MJ, Westerterp-Plantenga MS. Influence of consumption of a high-protein vs. high-carbohydrate meal on the physiological cortisol and psychological mood response in men and women. PLoS One. 2011;6:e16826.

27. Lemmens SG, Martens EA, Born JM, Martens MJ, Westerterp-Plantenga MS. Lack of effect of high-protein vs. high-carbohydrate meal intake on stress-related mood and eating behavior. Nutr J. 2011;10:136.

28. Haghighatdoost F, Azadbakht L. Dietary treatment options for depression among diabetic patient, focusing on macronutrients. J Diabetes Res. 2013;2013:421832.

29. Finger BC, Dinan TG, Cryan JF. High-fat diet selectively protects against the effects of chronic social stress in the mouse. Neuroscience. 2011;192:351-60.

30. Dallman MF, Pecoraro NC, la Fleur SE. Chronic stress and comfort foods: self-medication and abdominal obesity. Brain Behav Immun. 2005;19:275-80.

31. Pecoraro N, Reyes F, Gomez F, Bhargava A, Dallman MF. Chronic stress promotes palatable feeding, which reduces signs of stress: feedforward and feedback effects of chronic stress. Endocrinology. 2004;145:3754-62.

32. Finger BC, Dinan TG, Cryan JF. The temporal impact of chronic intermittent psychosocial stress on high-fat diet-induced alterations in body weight. Psychoneuroendocrinology. 2012;37:729-41.

33. Ortolani D, Oyama LM, Ferrari EM, Melo LL, Spadari-Bratfisch RC. Effects of comfort food on food intake, anxiety-like behavior and the stress response in rats. Physiol Behav. 2011;103:487-92.

34. Wallis DJ, Hetherington MM. Emotions and eating. Self-reported and experimentally induced changes in food intake under stress. Appetite. 2009;52:355-62.

35. Lattimore P, Maxwell L. Cognitive load, stress, and disinhibited eating. Eat Behav. 2004;5:315-24.
36. Parylak SL, Koob GF, Zorrilla EP. The dark side of food addiction. Physiol Behav. 2011;104:149-56.

37. Newman S, Pascal L, Sadeghian K, Baldo BA. Sweetened-fat intake sensitizes gamma-aminobutyric acid-mediated feeding responses elicited from the nucleus accumbens shell. Biol Psychiatry. 2013;73:843-50.

38. Schwab U, Lauritzen L, Tholstrup T, Haldorssoni T, Riserus U, Uusitupa M, et al. Effect of the amount and type of dietary fat on cardiometabolic risk factors and risk of developing type 2 diabetes, cardiovascular diseases, and cancer: a systematic review. Food Nutr Res. 2014;58:25145.

39. Vafeiadou K, Weech M, Sharma V, Yaqoob P, Todd S, Williams CM, et al. A review of the evidence for the effects of total dietary fat, saturated, monounsaturated and n-6 polyunsaturated fatty acids on vascular function, endothelial progenitor cells and microparticles. Br J Nutr. 2012;107:303-24.

40. Morrison CD, Huypens P, Stewart LK, Gettys TW. Implications of crosstalk between leptin and insulin signaling during the development of dietinduced obesity. Biochim Biophys Acta. 2009;1792:409-16.

41. Araújo TG, Leite AC, da Fonseca CS M, Carvalho BM, Schuler AR, Lima VL. High-fat diet based on dried bovine brain: an effective animal model of dyslipidemia and insulin resistance. J Physiol Biochem. 2011;67:371-9.

\section{Submit your next manuscript to BioMed Central and take full advantage of:}

- Convenient online submission

- Thorough peer review

- No space constraints or color figure charges

- Immediate publication on acceptance

- Inclusion in PubMed, CAS, Scopus and Google Scholar

- Research which is freely available for redistribution 